\title{
A THEORETICAL APPROACH TO FACILITATING TRANSITION PHASE MOTION IN A POSITIVELY BUOYANT AUTONOMOUS UNDERWATER VEHICLE
}

\author{
A R Palmer and G E Hearn, University of Southampton, UK \\ P Stevenson, National Oceanography Centre, Southampton, UK
}

\section{SUMMARY}

Positively buoyant autonomous underwater vehicles (AUVs) operate at survey speeds with a pitch angle that is maintained through application of the control surfaces, sufficient to generate hydrodynamic forces to counteract the excess buoyancy. To facilitate lower forward speeds and the ability to hover requires some additional method of control. This paper reviews possible options and then indicates how control can be achieved using a single or pair of through-body tunnel thrusters. New equations appropriate to AUVs are proposed and experimental results are used to estimate the equation parameters. These equations are used within a simulation of the Autosub AUV to determine the response of the AUV during the transition between survey and low speed operation. The results obtained from the simulations are analysed in terms of the performance of the AUV and the demanded energy levels to assess the feasibility of using tunnel thrusters as a low speed control device.

\section{NOMENCLATURE}

a Tunnel thruster model coefficient

A Tunnel thruster cross sectional area $\left(\mathrm{m}^{2}\right)$

$b \quad$ Tunnel thruster model coefficient

$b_{\mathrm{j}}^{\prime} \quad$ Propeller model coefficients $(j=1,2, \ldots, 9)$

$B \quad$ AUV buoyancy (N)

c Tunnel thruster model coefficient

$D \quad$ Tunnel thruster diameter (m)

E Energy (J)

$F, Q \quad$ Thruster force $(\mathrm{N})$ and torque $(\mathrm{Nm})$

$F_{\mathrm{LP}} \quad$ Force due to low pressure region $(\mathrm{N})$

$g \quad$ Acceleration due to gravity $\left(\mathrm{m} . \mathrm{s}^{-2}\right)$

$G \quad$ Steepness of thruster rotational speed allocation

$i \quad$ Subscript representing a time step

$I_{\mathrm{YY}} \quad$ AUV pitch moment of inertia $\left(\mathrm{kg} . \mathrm{m}^{2}\right)$

$j \quad$ Subscript representing the coefficient set for a regime of propeller operation

$J_{\mathrm{m}} \quad$ Motor/propeller inertia $\left(\mathrm{kg} . \mathrm{m}^{2}\right)$

$k \quad$ Gradient of moment arm

$k_{0} \quad$ Ratio of propeller rotational speed to vehicle speed at self propulsion

$k_{1} \quad$ Proportion of rotational speed for thruster 1

$k_{2} \quad$ Proportion of rotational speed for thruster 2

$K_{1} \quad$ Mass of fluid in tunnel thruster $(\mathrm{kg})$

$K_{2} \quad$ Thruster quadratic damping $\left(\mathrm{kg} . \mathrm{m}^{-1}\right)$

$K_{3} \quad$ Tunnel thruster model coefficient $\left(\mathrm{Ns}^{2}\right)$

$K_{\mathrm{F}} \quad$ Ratio of actual force to thruster static force

$K_{\mathrm{m}} \quad$ Motor torque constant $\left(\mathrm{kgm}^{2} \cdot \mathrm{s}^{-1}\right)$

$k_{\mathrm{p}} \quad$ Gradient of moment arm for thruster pair

$l \quad$ AUV length (m)

$m \quad$ AUV mass $(\mathrm{kg})$

$M \quad$ Pitch moment (Nm)

$M_{r s}^{\prime} \quad$ Non-dimensional variation of pitch moment with variables $r$ and $s$

$n \quad$ Thruster rotational speed $\left(\mathrm{s}^{-1}\right)$

$n^{\prime} \quad$ Propeller rotational speed ratio

$P \quad$ Power (W)

$P_{\mathrm{d}} \quad$ Pitch demand (rads)

$P_{\mathrm{dL}} \quad$ Pitch demand limit (rads)

$q \quad$ Pitch rate $\left(\operatorname{rads} . \mathrm{s}^{-1}\right)$

\author{
$Q_{\mathrm{m}} \quad$ Motor torque $(\mathrm{Nm})$ \\ $s \quad$ Thruster spacing (m) \\ $t \quad$ Time (s) \\ $u, v, w$ Surge, sway and heave velocity components \\ $\left(\mathrm{m} . \mathrm{s}^{-1}\right)$ \\ $u^{*} \quad$ Mid-transition speed $\left(\mathrm{m} . \mathrm{s}^{-1}\right)$ \\ $u_{\mathrm{i}} \quad$ Instantaneous velocity $\left(\mathrm{m} . \mathrm{s}^{-1}\right)$ \\ $u_{\mathrm{j}} \quad$ Thruster exit jet velocity $\left(\mathrm{m}^{-\mathrm{s}^{-1}}\right)$ \\ $u_{\mathrm{p}} \quad$ Fluid velocity at propeller $\left(\mathrm{m} . \mathrm{s}^{-1}\right)$ \\ $u_{\text {req }} \quad$ AUV required speed $\left(\mathrm{m} \mathrm{s}^{-1}\right)$ \\ $x, z \quad$ Longitudinal and vertical coordinate $(\mathrm{m})$ \\ $x_{\mathrm{B}}, z_{\mathrm{B}} \quad$ Longitudinal and vertical centre of buoyancy \\ (m) \\ $x_{\mathrm{LP}} \quad$ Moment arm of low pressure force $(\mathrm{m})$ \\ $x_{\mathrm{G}}, z_{\mathrm{G}} \quad$ Longitudinal and vertical centre of gravity (m) \\ $X_{\mathrm{S}}$ Force contribution from acceleration \\ ( $\mathrm{S} \equiv \mathrm{ACCEL}), \quad$ hydrodynamic $\quad(\mathrm{S} \equiv \mathrm{HYD})$, \\ hydrostatic ( $\mathrm{S} \equiv \mathrm{HYDST}$ ), rigid body $(\mathrm{S} \equiv \mathrm{RB})$, \\ control surfaces $(\mathrm{S} \equiv \mathrm{CS})$ and propeller \\ $(\mathrm{S} \equiv \mathrm{PROP})(\mathrm{N})$ \\ $X_{\mathrm{rs}}^{\prime} \quad$ Non-dimensional variation of surge force with \\ variables $r$ and $s$ \\ $Z_{\mathrm{rs}}^{\prime} \quad$ Non-dimensional variation of heave force with \\ variables $r$ and $s$ \\ $\alpha \quad$ Tunnel thruster performance measure \\ $\delta S \quad$ Sternplane deflection angle (rads) \\ $\theta \quad$ AUV pitch angle (rads) \\ $\kappa \quad$ Index representing time step for end of \\ transition zone \\ $v \quad$ Crossflow velocity $\left(\mathrm{m} \cdot \mathrm{s}^{-1}\right)$ \\ $\rho \quad$ Fluid density $\left(\mathrm{kg} . \mathrm{m}^{-3}\right)$ \\ $\sigma_{\mathrm{i}, \mathrm{S}} \quad$ Proportion of depth control at time step $i$ \\ undertaken by tunnel thruster $(\mathrm{S} \equiv \mathrm{TT})$ or control \\ surfaces $(\mathrm{S} \equiv \mathrm{CS})$ \\ $\omega, \xi, \psi$ Jet path model coefficients \\ $\Delta \sigma \quad$ Transition steepness of AUV controller
}

\section{INTRODUCTION}

Autosub is a large torpedo-shaped survey-style Autonomous Underwater Vehicle (AUV) designed for 
oceanographic research purposes. It has undertaken a wide variety of survey missions including the Autosub Under Ice programme [1]. The vehicle is equipped with a single stern-mounted open screw propeller and (forward of the propeller) a cruciform of four stern mounted control surfaces. The propeller provides the main propulsive force and the control surfaces provide depth and heading control at speed. The vehicle is ballasted to be positively buoyant so that it rises to the relative safety of the surface should the propulsion systems fail. To control the hydrostatic balance during survey operation the vehicle operates with a small negative (nose down) pitch angle, maintained by the control surfaces, which generates a hydrodynamic force equal and opposite to the positive buoyancy force. The vehicle particulars are given in Table 1.

Table 1: Autosub particulars

\begin{tabular}{|l|c|}
\hline Length & $7.0 \mathrm{~m}$ \\
\hline Diameter (max.) & $0.9 \mathrm{~m}$ \\
\hline Mass & $3600 \mathrm{~kg}$ \\
\hline Positive Buoyancy & $0.3 \%$ \\
\hline Survey Speed & $1.75 \mathrm{~m} . \mathrm{s}^{-1}$ \\
\hline
\end{tabular}

In order to expand the versatility of such an AUV, by permitting slower operational speeds or stationary investigations of situations of interest, additional means of overcoming the positive buoyancy characteristic must be provided when the control surfaces alone are no longer adequate. In this paper an AUV simulation is modified to facilitate such necessary control.

After an initial introduction to the simulation approach adopted alternative approaches of controlling positive buoyancy will be briefly reviewed. Thereafter throughbody tunnel thruster performance and modelling are discussed prior to demonstration of the effectiveness of such an approach to hydrostatic balance control for the case of a single thruster. The motivation to move from a single thruster to two thrusters is then considered as an introduction to an ongoing experimental programme to provide appropriate data and operational insight.

\section{AUV SIMULATION}

A six degree-of-freedom simulation of Autosub was developed using Matlab Simulink [2]. The simulation facilitates the examination of the performance of Autosub with different control strategies for undertaking different manoeuvres. The basic model has four key blocks, namely, a speed control block, a depth control block, a heading control block and a model block that calculates the AUV responses, see Figure 1. The three control blocks are adapted to match the vehicle performance being investigated. The AUV model block simulates the response of the vehicle using the equations of motion for the AUV. The equations of motion used are the Booth et al. [3] submarine equations with hydrodynamic derivatives assigned as determined from experiments [4]. The equations are arranged so that the vehicle accelerations are equated to the appropriate forces and moments acting on the AUV, see Equation (1).

$$
X_{\mathrm{ACCEL}}=\left(X_{\mathrm{HYD}}+X_{\mathrm{HYDST}}+X_{\mathrm{RB}}\right)+\left(X_{\mathrm{CS}}+X_{\mathrm{PROP}}\right) .
$$

The AUV model block is split into several parts to calculate different contributions to the forces and moments on the vehicle. These forces and moments are attributed to the hydrodynamic (HYD), hydrostatic (HYDST) and rigid body effects (RB), and the control forces and moments generated by the control surfaces (CS) and propeller (PROP). These contributions are summed and then integrated using a fourth order RungeKutta scheme. At each time step the state vector, which contains the vehicle position, orientation, velocity and rotation vectors, is updated. These newly calculated vectors are passed onto the control blocks and the simulation progresses until a user-specified endpoint has been reached. The simulations are undertaken using the Matlab Simulink variable time step approach, which varies the time step, limited by a maximum value, according to the noted changes in the state vector.

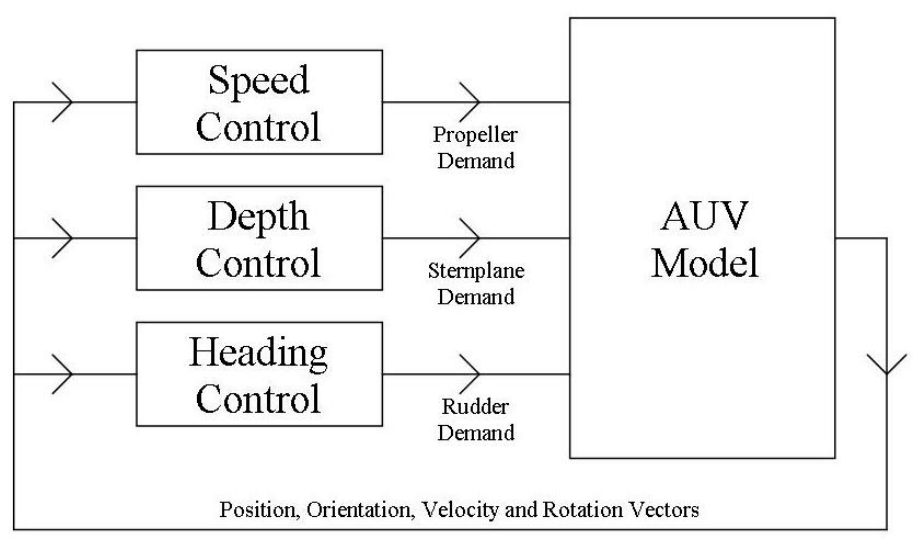

Figure 1: AUV simulation 
The aim of the research was to use the simulation tool to gain insight into the capability and control necessary to permit transition from AUV survey operation to low speed manoeuvring operations. In the initial investigation the simulation was restricted to motions in the vertical plane alone, that is, the sway, yaw and roll motions were neglected and the rudder was held fixed with zero deflection angle. The simulation continues to model the surge, heave and pitch motions controlled by the speed and depth control blocks.

The reduced equations of motion used in the simulation are given as Equations (4), (5) and (6). Since the sway velocity, $v$, is zero, then $v=\sqrt{v^{2}+w^{2}}=|w|$.

The stern propeller is assumed to only generate a force in the vehicle longitudinal direction $(x)$ and the propeller torque is not modelled. The speed control block takes a required operational forward speed as the input and outputs a command to increase or decrease the propeller force as appropriate. The model block uses a quadratic representation of the propeller thrust characteristics expressed in terms of a rotational speed ratio, defined as:

$$
n^{\prime}=\frac{n}{k_{0} u}=\frac{u_{\text {req }}}{u} \text {. }
$$

Here $k_{0}$ is the ratio of the rotational speed of the propeller to the vehicle speed at self propulsion; hence $k_{0} u$ gives the rotational speed necessary to maintain the vehicle speed. Using this ratio the propeller force model is:

$$
X_{\text {PROP }}=0.5 \rho l^{2} u|u|\left(b_{\mathrm{j}}^{\prime}+b_{\mathrm{j}+1}^{\prime} n^{\prime}+b_{\mathrm{j}+2}^{\prime}\left(n^{\prime}\right)^{2}\right) .
$$

The coefficient set, $b_{\mathrm{j}}^{\prime}, b_{\mathrm{j}+1}^{\prime}$ and $b_{\mathrm{j}+2}^{\prime}$, used with $j=1,4$ or 7 , depends upon the regime of operation for the propeller as determined by the value of $n^{\prime}$. The coefficient sets reflect the differing propeller performance in differing regimes of operation and are determined from the propeller characteristics.

The depth control is undertaken using a simple control module, which combines both depth and pitch control [5]. This is illustrated in Figure 2.

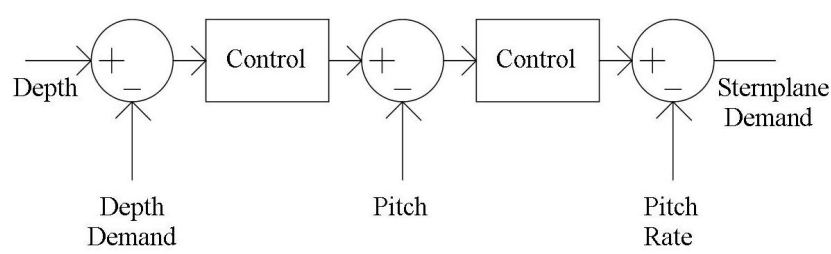

Figure 2: Depth controller

Having briefly outlined the basic control blocks and indicated the form of the actual motion equations used the earlier cited transition phase motion is addressed next.

Surge:

$$
\begin{aligned}
m\left[\dot{u}+w q-x_{\mathrm{G}} q^{2}+z_{\mathrm{G}} \dot{q}\right]=0.5 \rho l^{2} & \left(X_{\mathrm{uu}}^{\prime} u^{2}+X_{\mathrm{ww}}^{\prime} w^{2}+X_{\mathrm{uu} \delta \delta \mathrm{S}}^{\prime} u^{2} \delta S^{2}\right) \\
& +0.5 \rho l^{3}\left(X_{\dot{\mathrm{u}}}^{\prime} \dot{u}+X_{\mathrm{wq}}^{\prime} w q\right) \\
& +0.5 \rho l^{4} X_{\mathrm{qq}}^{\prime} q^{2} \\
& +(B-m g) \sin \theta+X_{\mathrm{PROP}}
\end{aligned}
$$

Heave:

$$
\begin{aligned}
& m\left[\dot{w}-u q-z_{\mathrm{G}} q^{2}-x_{\mathrm{G}} \dot{q}\right]=0.5 \rho l^{2}\left(Z_{\mathrm{uw}}^{\prime} u w+Z_{\mathrm{wv}}^{\prime} w v+Z_{\mathrm{uu} \delta \mathrm{S}}^{\prime} u^{2} \delta S\right) \\
& +0.5 \rho l^{3}\left(Z_{\dot{\mathrm{w}}}^{\prime} \dot{w}+Z_{\mathrm{uq}}^{\prime} u q+Z_{\mathrm{u}|\mathrm{q}| \delta S^{\prime}}^{\prime} u|q| \delta S+Z_{\mathrm{wv}\left|\frac{\mathrm{q}}{\mathrm{w}}\right|}^{\prime}|w v| \frac{q}{w} \mid\right) \\
& +0.5 \rho l^{4} Z_{\dot{\mathrm{q}}}^{\prime} \dot{q} \\
& +(m g-B) \cos \theta
\end{aligned}
$$

Pitch:

$$
\begin{aligned}
& I_{\mathrm{YY}} \dot{q}+m\left[z_{\mathrm{G}}(\dot{u}+w q)-x_{\mathrm{G}}(\dot{w}-u q)\right]=0.5 \rho l^{3}\left(M_{\mathrm{uw}}^{\prime} u w+M_{\mathrm{uu} \delta \mathrm{S}}^{\prime} u^{2} \delta S+M_{\mathrm{wv}}^{\prime} w v\right) \\
& +0.5 \rho l^{4}\left(M_{\dot{\mathrm{w}}}^{\prime} \dot{w}+M_{\mathrm{uq}}^{\prime} u q+M_{\mathrm{qv}}^{\prime} q v+M_{\mathrm{u}|\mathrm{q}| \delta \mathrm{S}}^{\prime} u|q| \delta S\right) \\
& +0.5 \rho l^{5} M_{\dot{\mathrm{q}}}^{\prime} \dot{q} \\
& -\left(m g x_{\mathrm{G}}-B x_{\mathrm{B}}\right) \cos \theta-\left(m g z_{\mathrm{G}}-B z_{\mathrm{B}}\right) \sin \theta
\end{aligned}
$$




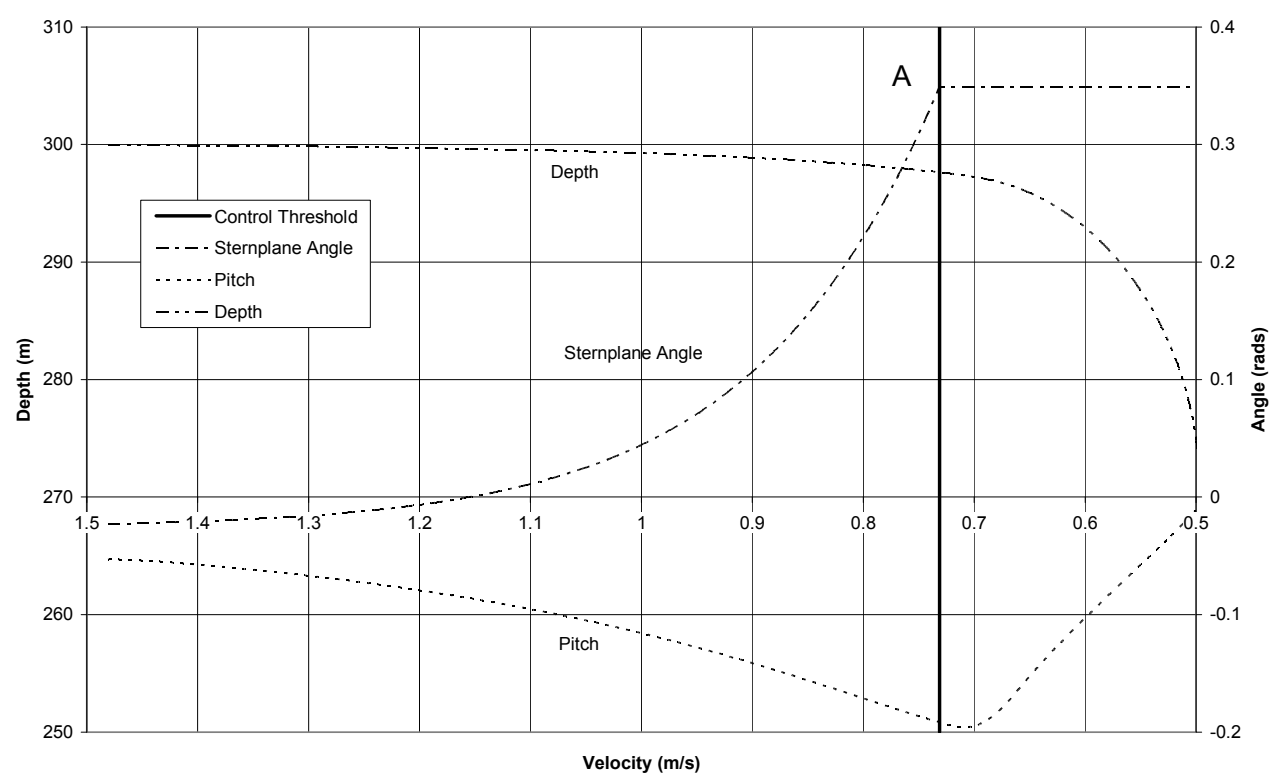

Figure 3: Transition zone using original AUV configuration

\section{THE TRANSITION PHASE}

The simulation tool is used to demonstrate the behaviour of the AUV, in its original survey configuration, as the operational mode changes from constant speed survey operation to the zero forward speed (hover) condition. The reduction in required forward speed is taken at a constant rate. Figure 3 shows the sternplane, pitch and depth response of the vehicle as the forward speed is reduced.

The vehicle starts at a depth of $300 \mathrm{~m}$ travelling at $1.5 \mathrm{~m} . \mathrm{s}^{-1}$ with a small sternplane deflection and corresponding pitch angle to generate the force required to counteract the inherent positive buoyancy. As the vehicle begins to slow down the speed dependence of the generated hydrostatic balance control force means that the pitch angle must increase to maintain depth. Therefore the depth control block alters the sternplane deflection angle to increase the pitch angle. As the speed continues to reduce the maximum deflection of the control surfaces is reached, marked by the control threshold at point A. Here the control surfaces can no longer generate sufficient force to maintain the required pitch angle to operate at constant depth. Hence the vehicle depth decreases indicating that the vehicle is rising towards the surface. Furthermore, the pitch angle returns towards zero due to the vehicle's righting moment. This simulation shows that in order to operate at speeds below $0.73 \mathrm{~m} \cdot \mathrm{s}^{-1}$ (point A) an alternative method of controlling the hydrostatic balance is required.

The maximum deflection angle for the control surfaces is set at $20^{\circ}$ (for practical reasons) to try to avoid the onset of stall. In fact the simulations do not model stall and the stall angle (and hence maximum lift force obtainable) will reduce with decreasing Reynolds number.

\subsection{ALTERNATIVE APPROACHES TO CONTROLLING POSITIVE BUOYANCY}

There are several approaches to controlling the hydrostatic balance and these can be broadly classified into two categories. The first of these is the use of external systems and the second is internal systems.

External systems require devices to be attached to the outside of the vehicle and are dominated by propeller based thrusters, arranged in various configurations (similar to a Remotely Operated Vehicle (ROV)) [6], but also includes some biomimetic approaches [7] to force generation (flapping foils).

The internal systems demand use of internal space and include variable buoyancy systems [8] and methods that extend the current (survey) approach by maintaining a vehicle pitch angle using non-speed dependent methods such as control moment gyros [9] or moving mass systems [10].

A key aim in the development of survey-style AUVs is to add the ability to hover and undertake low speed manoeuvres to facilitate interaction with the discovered environment. As this aim requires the addition of further control devices it appears logical to control the hydrostatic balance using a system which enables both hovering and low speed manoeuvring. The most obvious choice for hydrostatic balance control would be to neutralise the buoyancy using a variable buoyancy system. However, this removes the safety net associated with being positively buoyant, it would require 
considerable internal space and the responsiveness and power requirements would not be suitable for low speed manoeuvring at depth. These factors point towards the use of externally mounted thrusters as these systems are relatively simple, can provide forces throughout the entire speed range and offer good responsiveness. Approaches to vertical motion control using an external thruster are discussed in the development of the Nereus AUV [11].

A further factor in the development of survey-style AUVs is to try to retain the existing survey efficiency, where possible, creating a multi-purpose vehicle. Mounting external thrusters on a torpedo style AUV can cause a substantial drag penalty (an increase of the order of $15 \%$ ) and increase the overall dimensions. These problems are overcome by mounting the thrusters in through-body tunnels. A drawback of mounting the thrusters in tunnels is that this removes the potential flexibility in terms of the thrust-vectoring achievable with externally mounted thrusters.

For this investigation into the control of survey-style AUVs operating in the transition phase the vehicle will be modelled with a single centrally mounted vertical tunnel thruster. The tunnel thruster only generates a force in the vertical plane of the vehicle and, initially, the influence of the thruster on the vehicle pitch is neglected.

Further to these assumptions, the drag penalty due to the presence, or operation, of the tunnel thruster is not modelled and the presence, or operation, of the tunnel thruster is assumed to not affect the vehicle in any other way. The last two assumptions allow the hydrodynamic derivatives determined from experiments using the unmodified vehicle to be retained for the new simulations. These equations are not suited to high angle-of-attack low speed manoeuvres; therefore the simulation is restricted to assessing the performance in the transition zone. These assumptions neglect some of the effects of the interaction of the thruster jet flow with the vehicle and the modified pressure distributions created. These effects are not fully understood at this time and hence are a subject for further research.

Having selected through-body tunnel thrusters and indicated assumptions to be made when undertaking the simulations the next task is to address the modelling of the selected thrusters.

\section{MODELLING TUNNEL THRUSTER PERFORMANCE}

An important consideration for enhancing the simulation of an AUV undergoing transition is the provision of the required additional thruster control. In this case a model of the force generated by a tunnel thruster under the various operational conditions is needed. A review of tunnel thruster performance and modelling over a complete plane of operation is included in [12].
4.1

\section{PERFORMANCE AT ZERO SPEED OF ADVANCE}

The performance of a tunnel thruster at zero speed of advance is analogous to the static conditions used in thruster characterisation experiments. Thus, the thrust generated can be expected to be proportional to the square of the thruster rotational speed [13].

\subsection{PERFORMANCE ON A VEHICLE UNDERGOING FORWARD MOTION}

The performance of a tunnel thruster on a vehicle, undergoing forward motion, is more complicated due to the interaction of the ambient flow around the vehicle with the jet emitted from the thruster exit. Experimental results for a submersible operating in this condition [14] show a large decrease in the force experienced by the vehicle compared to the equivalent static thrust. Figure 4 illustrates these results. The effective force is presented as a fraction of the equivalent static thrust, $K_{\mathrm{F}}$, against the speed ratio of the vehicle speed, $u$, to the thruster exit jet speed, $u_{\mathrm{j}}$.

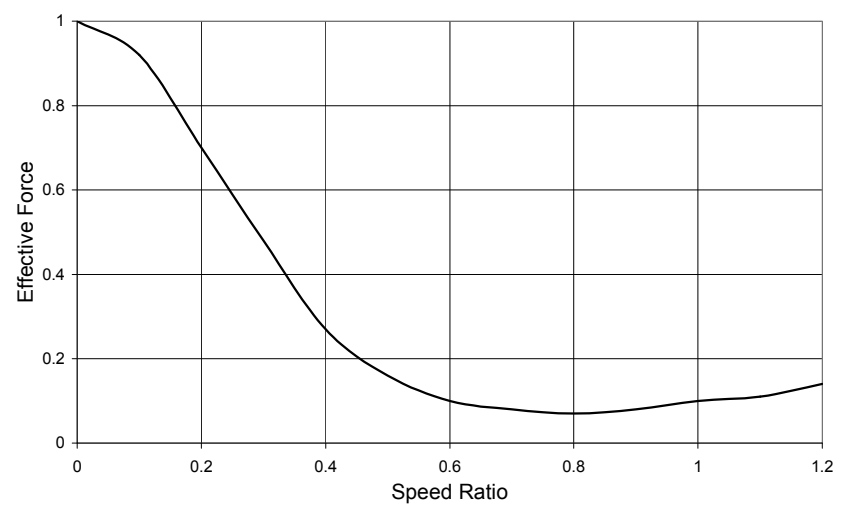

Figure 4: Variation in effective force with speed ratio, $u / u_{\mathrm{j}}[14]$

The decrease in the effective force is not due to a change in the performance of the thruster unit itself, but is attributed to the complex flow conditions generated by the interaction of the thruster exit jet flow with the ambient flow around the vehicle [15]. (The flow conditions at the inlet are not thought to have a significant impact on the effective force [16].) The interaction causes a low pressure region downstream of the jet exit (see Figure 12). This causes a suction force that opposes the thruster force.

Whereas Figure 4 presents data in terms of the speed ratio, some authors show the decrease in effective force is solely a function of the ambient flow speed and therefore independent of the jet speed (and hence thrust) $[16,17]$. Furthermore, detailed experimental studies of jets emitting from flat plates into ambient flows have shown that for low speed ratios the jet dominates the ambient flow. Hence the low pressure region is created solely by the induced separation of the ambient flow boundary layer $[18,19]$. That is, for low speed ratios the 
reduction in effective force is solely a function of the ambient flow speed and is independent of the jet exit speed.

However, as an AUV undergoes transition the range of forward speeds experienced means it would not be valid to assume that the thruster is always operating at low speed ratios. Further to this, the dependence of the interaction between the jet and crossflow on the development of the boundary layer over the body makes the performance of each different vehicle configuration unique.

Therefore a set of experiments was undertaken [20] to assess the performance of a tunnel thruster on a torpedoshaped AUV over a wide range of forward speeds and small yaw (or by symmetry, pitch) angles. These experiments yielded the effective force against speed ratio relationship presented in Figure 5. The results showed a consistent trend of dependency on the speed ratio rather than forward speed, with minimal variation resulting from the small yaw angles investigated. Having illustrated similar trends between Figures 4 and 5 a method of modelling the thruster is presented.

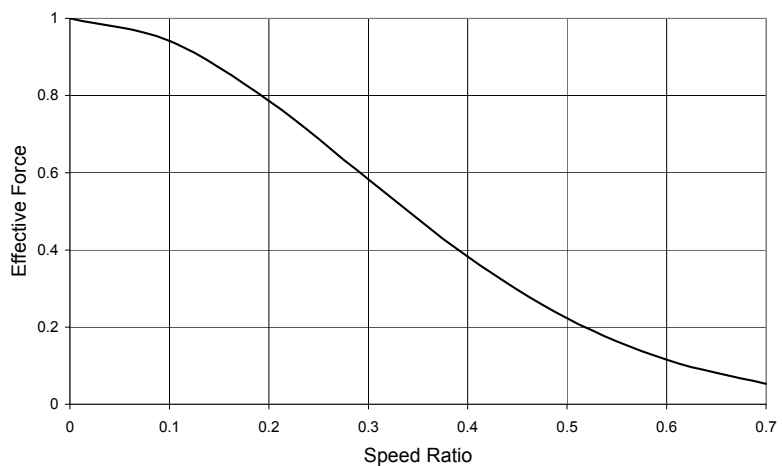

Figure 5: Variation in effective force with speed ratio determined by experiment [20]

\subsection{MODELLING UNDERWATER THRUSTERS}

The steady state performance of propeller based thrusters has been studied extensively in the development of surface vessels (see for example [21]). However, the dynamic performance of a thruster can dominate the overall control of an underwater vehicle at low speeds [22]. Hence, over the past two decades there has been a series of developments in the modelling of underwater thrusters focussing on their dynamic performance.

The first group of models were based on considering the thruster and tunnel as a control volume and applying momentum and energy theorems to derive relationships between the generated thrust, $F$, and torque, $Q$, and the flow through the thruster, $u_{p}[23,24]$. These relationships are combined with a model of the motor and blade element relations. One such model [25] can be summarised as follows:

$$
\begin{aligned}
& J_{\mathrm{m}} \dot{n}+K_{\mathrm{m}} n=Q_{\mathrm{m}}-Q \\
& K_{1} \dot{u}_{\mathrm{p}}+K_{2}\left(u_{\mathrm{p}}-u\right)\left|u_{\mathrm{p}}-u\right|=F \\
& F=F\left(n, u_{\mathrm{p}}\right) \quad Q=Q\left(n, u_{\mathrm{p}}\right)
\end{aligned}
$$

Here $J_{\mathrm{m}}$ is the motor inertia, $n$ is the rotational speed of the thruster, $Q_{\mathrm{m}}$ is the motor control torque, $K_{\mathrm{m}}$ is the motor torque constant, and $K_{1}$ and $K_{2}$ are constants representing the mass of fluid in the tunnel thruster and the thruster quadratic damping. Developments of these models include more accurate representations of the lift and drag characteristics of the blade sections for use in the blade element relations for the functions $F$ and $Q$ [26].

These improved models were found to work well with zero ambient flow, however their performance reduces in other conditions. This weakness led to the development of models that include a simplified representation of the vehicle dynamics to estimate the flow into the thruster and the use of propeller characteristics, derived from open water charts [27]. Recent developments include more accurate representations of the propeller open water characteristics [28].

\subsection{MODELLING TUNNEL THRUSTERS}

The original thruster models [23, 24] were developed by considering simplified representations of tunnel thrusters and comparing these models with experimental results. However, the loss of performance when the ambient flow is no longer zero and the fact that the effective force acting on the vehicle is required, rather than the actual thruster force, meant that new models became desirable.

A literature survey for tunnel thruster performance models on a moving underwater vehicle found only one model. This was developed using experimental data [29]. The authors tested the performance of the thruster in three different operating modes, namely: forward travel, low speed manoeuvring and high speed turning. The basis model used was similar to Equation (7). It was found that the dynamic performance of the thruster was not significantly altered by the operating mode of the vehicle; however the steady state performance was affected. This led to the development of an augmented model:

$$
F=K_{1} \dot{u}_{\mathrm{p}}+a+b n|n|,
$$

where $a$ and $b$ are determined from a look-up table of experimental results. An attempt to incorporate the vehicle forward speed into the basic model was found to be unsuccessful. The authors reported that the augmented model successfully captures the effects of forward speed and yaw angle on the performance of a tunnel thruster. However, the model only considers the thruster forces and no account was made for the ambient flow effects.

Other AUV simulations incorporating tunnel thrusters have simply assumed the performance of the thruster is 
unaffected by the ambient flow conditions and thus the force applied is that generated by the thruster with a moment arm defined by the location of the thruster [30].

Tunnel thrusters are similar in both their design and use to the secondary (commonly, bow) thrusters found on surface vessels. A literature survey for these types of models again yielded few results. A simple model [31], which calculates the force on the vessel depending on the vessel forward speed alone, has the form:

$$
F=K_{3} n|n| \exp \left[-c u^{2}\right]
$$

where $K_{3}$ and $c$ are constants. This exponential form can be used to accurately model the variations in effective force when the force is decreasing, that is, at the low speed ratios the model is designed for, but deviates from the experimental data as the force recovers at higher forward speeds (as seen on surface vessel data). Manoeuvring simulations performed at the Marine Research Institute Netherlands (MARIN) on vessels with secondary thrusters use a series of coefficients from lookup tables relating the performance under given conditions to the equivalent static performance as derived from a series of experiments on representative hull forms [32].

\subsection{A PROPOSED AUV TUNNEL THRUSTER MODEL}

The preceding sections and literature review have found no published and established modelling approach for tunnel thrusters, either on AUVs or surface vessels. It is believed that this is due to the complexity of the flow phenomena generated and the dependence on the particular configuration in question. Furthermore, there is uncertainty over the effect of the operation of the tunnel thruster on the vehicle as a whole, that is, the change in performance of the vehicle due to the interaction of the exit jet flow with the vehicle downstream of the tunnel thruster.

To attempt to increase the understanding of the performance of a vehicle using tunnel thrusters and to gain insight into how to control an AUV it is important to be able to model the tunnel thruster as accurately as possible. To achieve this a simple model of the static performance has been developed. The recently measured experimental results [20] support the conclusion from [29] that the dynamic performance of the thruster is unchanged by the ambient flow conditions and hence a model such as Equation (7) can be used for the dynamic performance.

At zero (and very low) speed of advance the thruster can be assumed to operate as the static performance and thus the thrust can be assumed to be proportional to the square of the rotational speed, that is:

$$
F=K_{3} n|n|
$$

On a vessel undergoing forward motion the thruster performance is simply the static performance factored by an exponential reduction based on the speed ratio, that is:

$$
F=K_{3} n|n| \exp \left[-c\left(\frac{u}{u_{\mathrm{j}}}\right)^{2}\right] .
$$

The novel tunnel thruster model of Equation (11) has been incorporated into the AUV model block of the earlier cited simulation as an additional force in the heave equation. The model coefficients, $K_{3}$ and $c$, were selected using a least squares fit to the experimental data [20] and assume the values 0.90 and 6.69 respectively.

\section{THRUSTER AND STERNPLANE CONTROL INTERCHANGE}

Tunnel thrusters require considerable amounts of energy and their performance varies according to the operational conditions of the vehicle. Therefore, on an energy limited vehicle, their use is restricted to situations where they are the only suitable method of control. Hence they will only be used to control the hydrostatic balance during low speed manoeuvring operation, when the control surfaces can no longer undertake this task, and for hovering. Thus an interchange between the methods of controlling the hydrostatic balance as the vehicle goes through the transition phase is required.

The approach used here uses an interchange function [33] to determine the proportion of the control given to each system. The proportion given to the thruster (TT) and control surfaces (CS) respectively at time step, $i$, is:

$$
\sigma_{\mathrm{i}, \mathrm{TT}}=1-0.5\left[\tanh \left(\frac{u_{\mathrm{i}}-u^{*}}{\Delta \sigma}\right)+1\right]
$$

and

$$
\sigma_{\mathrm{i}, \mathrm{CS}}=1-\sigma_{\mathrm{i}, \mathrm{TT}}
$$

The proportion of the control is determined as a function of the vehicle forward speed and two user-defined parameters, namely, the mid-transition speed, $u^{*}$, and the 'steepness' of the transition zone, $\Delta \sigma$. A low value of the 'steepness' parameter gives a step change in the control demand at the mid-transition speed, whereas a high value gives a longer smooth transition (centred about the midtransition speed). The depth error is factored by the proportion of the control for each system and is sent to the individual controllers.

The original depth control block has now been split into two parts, namely, a tunnel thruster control module and a control surface control module. These modules have joint control over the depth of the vehicle with the control surface control module retaining the pitch control elements of the original depth control block.

\subsection{TUNNEL THRUSTER CONTROL MODULE}

The tunnel thruster is controlled using a ProportionalIntegral Derivative (PID) controller. It takes the depth 
error as its input and outputs a thruster rotational speed. The proportional and derivative terms have constant gains applied to them, but the integral term has a variable gain. The integral gain is factored by the result of the interchange function, Equation (12), to increase or decrease the amount of integral control used depending on the speed of the vehicle. The integrator also has a reset function that is activated by the vehicle speed exceeding the upper limit of the transition zone (where the tunnel thrusters are not to be used).

\subsection{CONTROL SURFACE CONTROL MODULE}

The control surface control module is the same as the original depth control module with the depth error as its input and the sternplane deflection angle as the output. The integral term of the depth control part of the module is modified in the same way as the integral term of the tunnel thruster control module, but with the integrator reset activated by the vehicle speed becoming lower than the lower limit of the transition zone.

\section{SIMULATION DETAILS}

The thruster assisted AUV simulations have been undertaken at five different decelerations, with five different values of the transition 'steepness' and eight different values of the mid-transition speed. The decelerations used are chosen to represent gradual flightpath-style transition phases and the mid-transition speeds are chosen to cover the entire range of operability for the control surfaces. The specific values used are given in Table 2 .

Table 2: Control variables for simulations

\begin{tabular}{|c|c|c|}
\hline Deceleration & Steepness & Mid-Transition Speed \\
\hline$\left(\mathrm{m}^{-2} \mathrm{~s}^{-2}\right)$ & - & $\left(\mathrm{m}^{-1}\right)$ \\
\hline-0.005 & 0.01 & 0.5 \\
\hline-0.0075 & 0.10 & 0.5625 \\
\hline-0.01 & 0.15 & 0.625 \\
\hline-0.0125 & 0.20 & 0.75 \\
\hline-0.015 & 0.30 & 0.875 \\
\hline \multirow{2}{*}{} & 1.0 \\
\cline { 2 - 3 } & 1.125 \\
\cline { 2 - 3 } & \\
\cline { 3 - 3 }
\end{tabular}

The results of the simulations will be analysed in two different ways. Firstly, the ability of the vehicle to control itself will be assessed by examining the variations in depth and pitch. Secondly, the amount of energy required for the different approaches will be calculated. Energy is chosen as a measure of the performance, as this is a key factor for an energy limited vehicle and hence an understanding of the impact of certain approaches is necessary.

To calculate the energy it is necessary to define the limits for the calculation. The starting point is simple, that is, the point at which the vehicle begins to slow down. The end point is less well defined. The choice is based upon whether (a) the transition period is considered to end at a common point in time, regardless of the intervening events, or, (b) the transition period ends when the vehicle reaches a steady state hovering condition. The latter will inevitably be a function of how the transition is undertaken and will be different for each simulation. Both of these conditions were examined and the results are presented in Section 6.2.

Here option (a) was implemented as the latest time, of the entire set, for the steady state hovering condition to be achieved during a set of simulations. Option (b) is taken as the time in an individual simulation when the steady state hovering condition is achieved. The hovering condition is assumed to have been achieved when the AUV is within a certain distance of the target depth, arbitrarily set at $\pm 2 \mathrm{~cm}$. A set of simulations are those runs with a common level of deceleration and steepness, that is, only mid-transition speed is variable.

The energy required by the thruster is calculated by numerically integrating the power drawn over the time period selected according to option (a) or (b). The thrust, $F$, is calculated in accordance with Equation (10) and is converted to power using the momentum theory based relationship [13]:

$$
P=\frac{F^{3 / 2}}{2 \alpha^{3 / 2} \sqrt{\rho A}} .
$$

Here $\alpha$ is a measure of the performance of the thruster, compared to an ideal thruster, taken to be 0.55 using a review of available commercial thruster performance and surface vessel bow thruster data. That is, the required energy is given by:

$$
E=\sum_{i=1}^{\kappa} \frac{\left(K_{3}\left(\frac{n_{i}+n_{\mathrm{i}-1}}{2}\right)^{2}\right)^{3 / 2}}{2 \alpha^{3 / 2} \sqrt{\rho A}}\left(t_{\mathrm{i}}-t_{\mathrm{i}-1}\right) .
$$

$\kappa$ is an index representing the number of time steps at the end of the transition zone. Results generated are now discussed.

\subsection{TIME HISTORY VARIATION OF AUV RESPONSES}

Figures 6 and 7 provide depth time histories and their variation with mid-transition speed and steepness for the vehicle undergoing transition with a deceleration of $-0.01 \mathrm{~m} . \mathrm{s}^{-2}$. The simulation starts with the vehicle travelling at $1.5 \mathrm{~m} . \mathrm{s}^{-1}$ and the deceleration starts at $t=$ 200 s with zero forward speed being reached at approximately $t=350 \mathrm{~s}$.

These figures show that the depth change is more sensitive to mid-transition speed than steepness. In general the depth changes are small in magnitude (relative to the size of the vehicle) and larger for lower mid-transition speeds and smoother transitions. These depth changes are not expected to be a problem unless 
the transition zone is undertaken in restricted waters or this zone coincides with other depth sensitive mission operations.

Figures 8 and 9 show the pitch time histories for the same simulations. These figures yield similar conclusions to the depth time histories, with a much greater dependence on mid-transition speed and larger pitch changes for lower mid-transition speeds. However, a smoother transition gives a smaller pitch change. Once the pitch change has been recovered from the initial speed reductions all the simulations show small amplitude pitch oscillations that continue into the steady state hovering operation. The amplitude of the oscillations is generally lower with higher mid-transition speeds.

Examining the results presented, and those for the other decelerations, shows that in order to maintain control over pitch, that is, to ensure a smooth variation in pitch and reduce the pitch oscillations, the transition zone should be taken slowly and with a high mid-transition speed. In effect this approach allows the control surfaces a certain length of time (while the majority of the depth control is undertaken by the tunnel thruster) and when the forward speed is high enough pitch fluctuations will be controlled successfully.

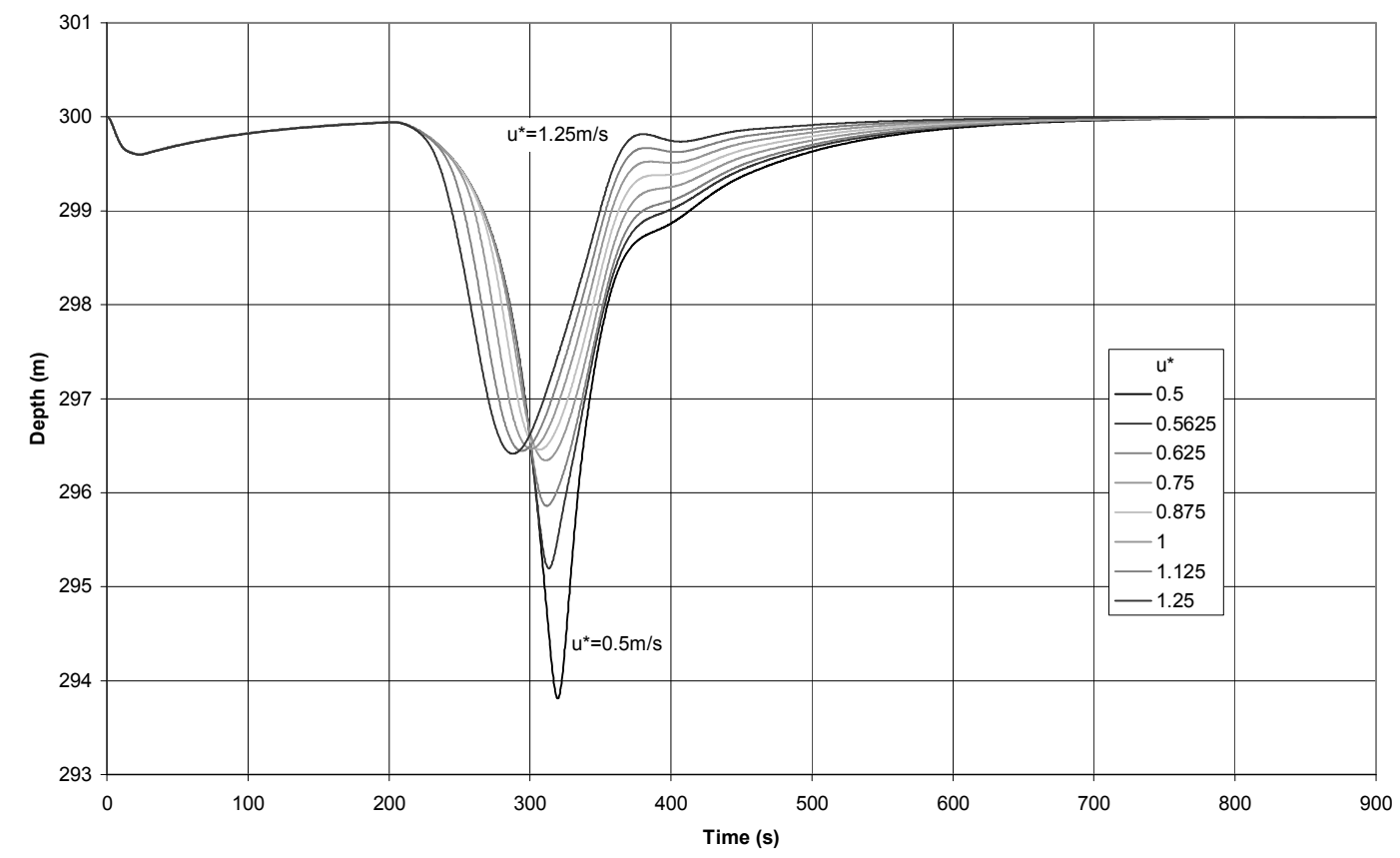

Figure 6: Depth time history for fixed $\Delta \sigma=0.1$ and variable $u^{*}$

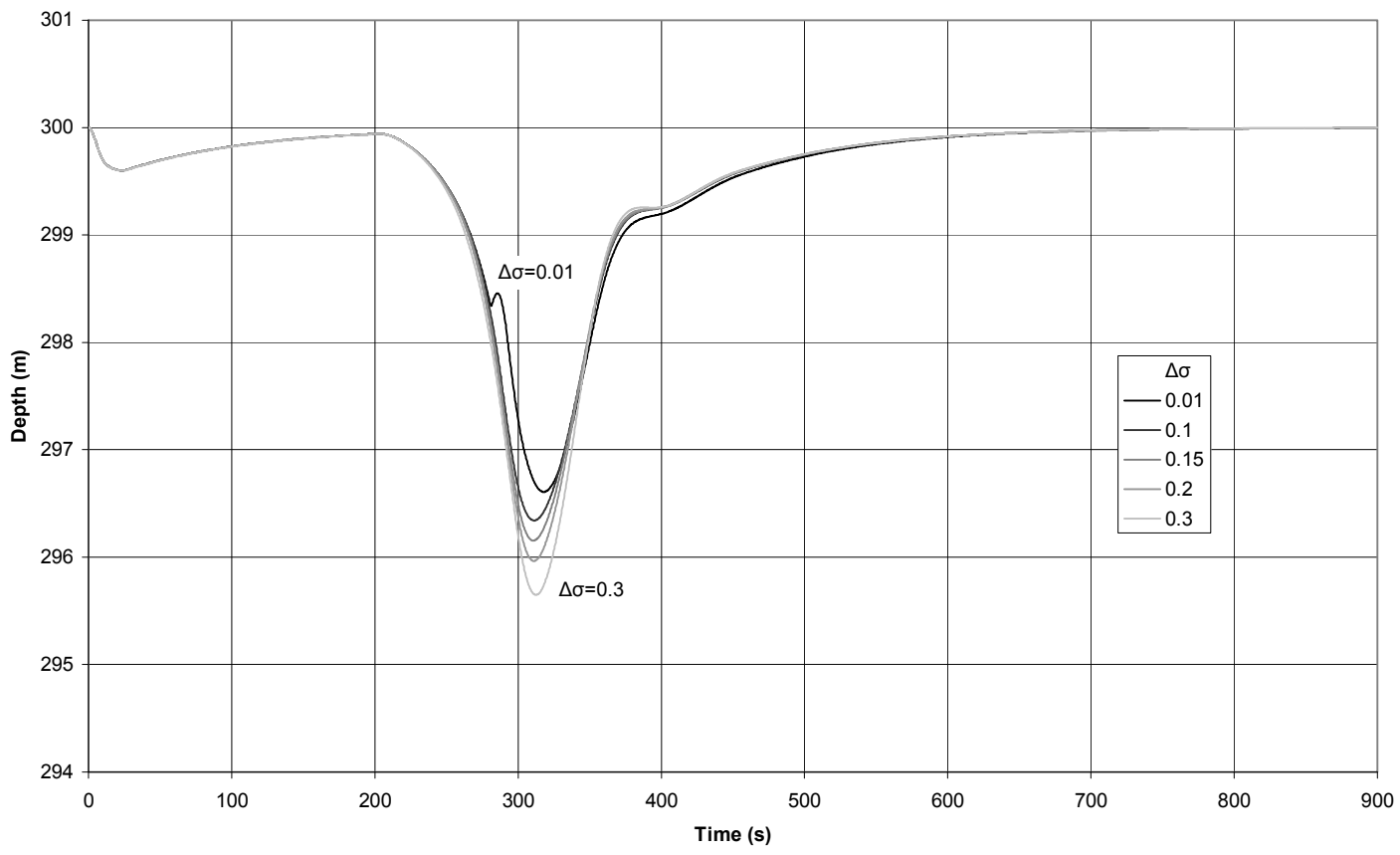

Figure 7: Depth time history for fixed $u^{*}=0.75 \mathrm{~m} . \mathrm{s}^{-1}$ and variable $\Delta \sigma$ 


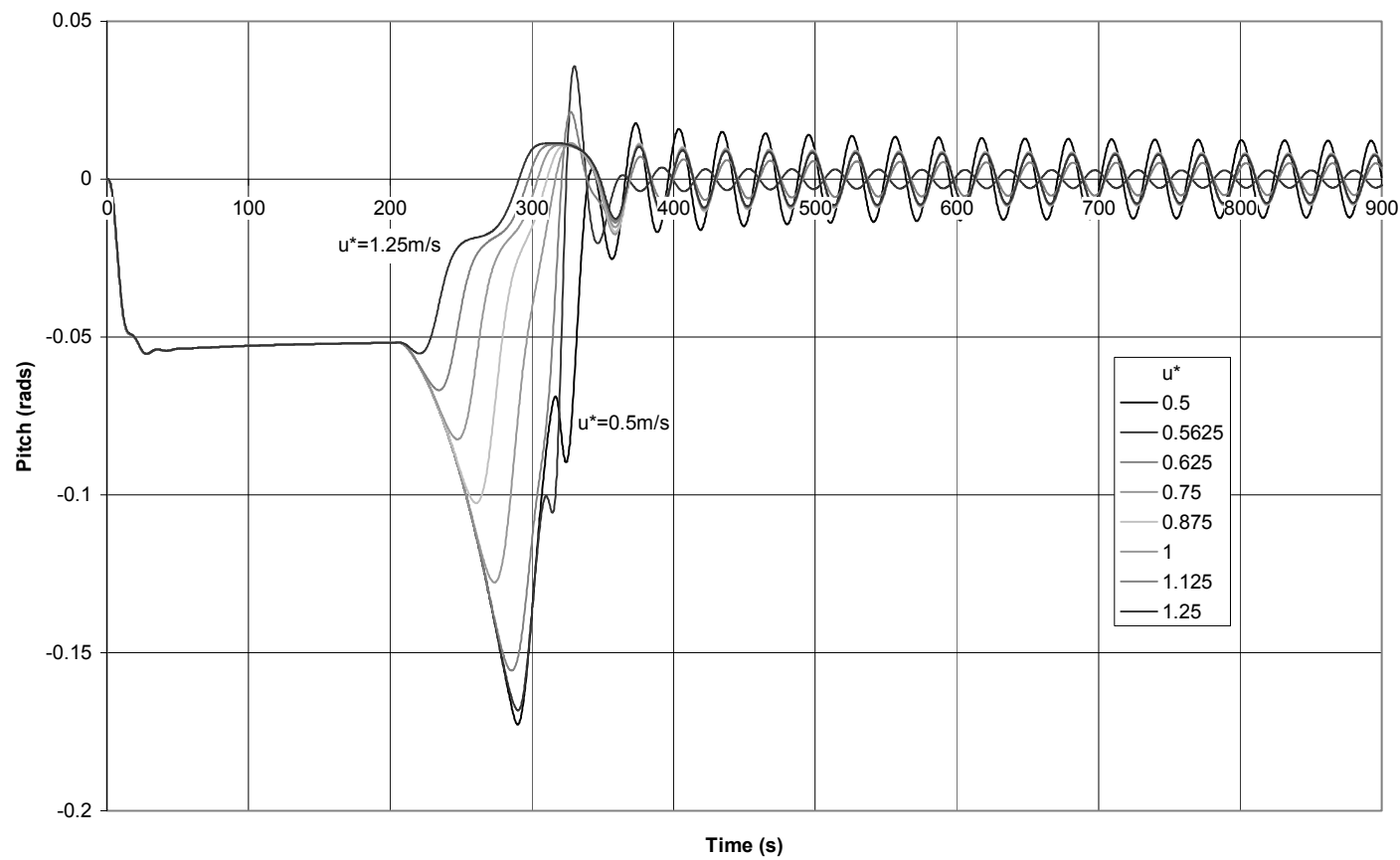

Figure 8: Pitch time history for fixed $\Delta \sigma=0.1$ and variable $u^{*}$

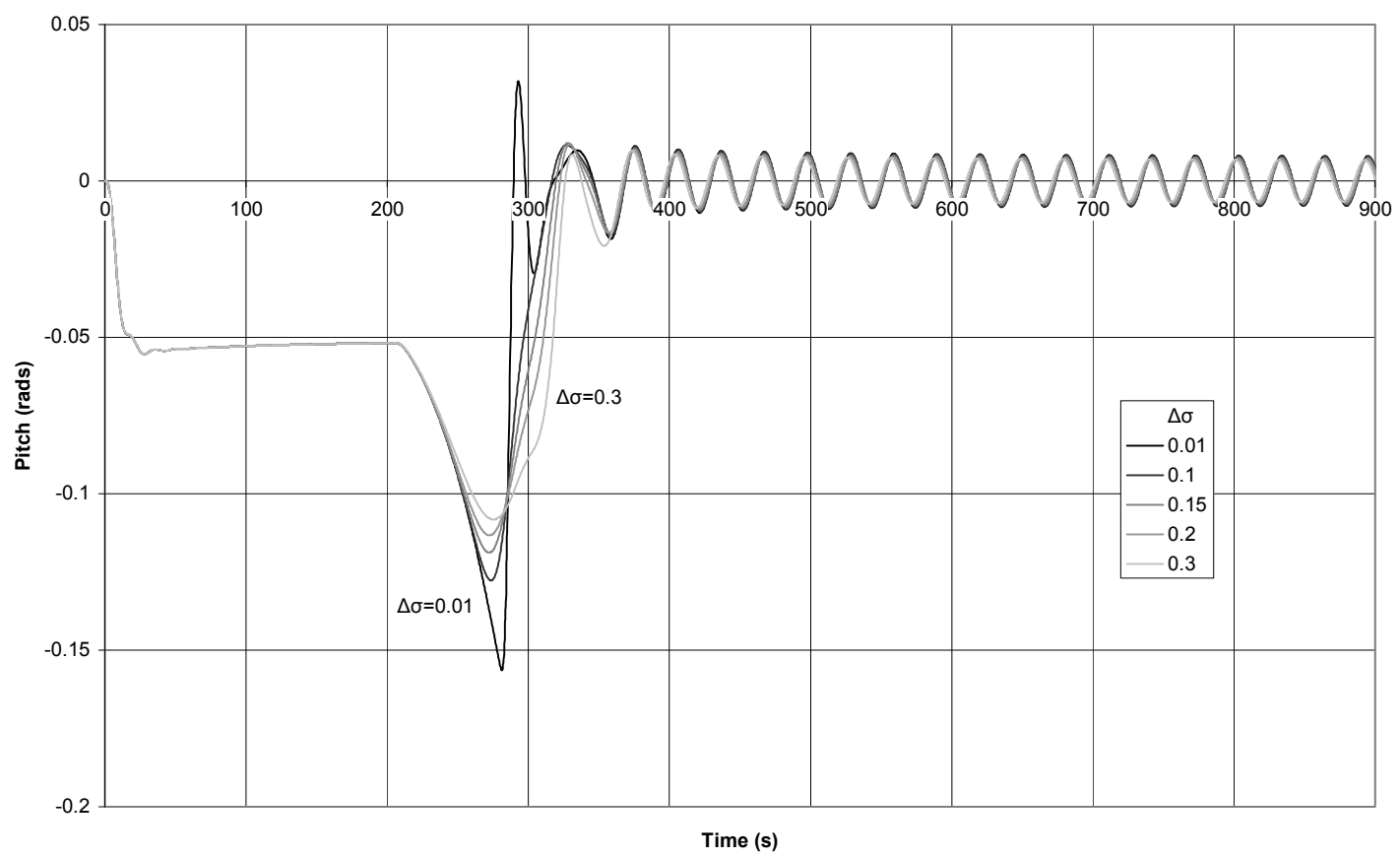

Figure 9: Pitch time history for fixed $u^{*}=0.75 \mathrm{~m} \cdot \mathrm{s}^{-1}$ and variable $\Delta \sigma$

Examination of the depth, pitch, thruster rotational speed and control surface time histories across the cited range of decelerations show variations are greater according to the length of time spent at a particular speed rather than the rate of change of speed. That is, the lower decelerations mean a greater time at each speed and hence the overall depth and pitch changes are the largest, but these changes are then recovered at a higher speed than for faster decelerations.

\subsection{VARIATION OF ENERGY REQUIREMENTS AS A FUNCTION OF THRUSTER CONTROL PARAMETERS}

A representative set of calculated energy results are presented in Figures 10 and 11 for a deceleration of $-0.01 \mathrm{~m} \cdot \mathrm{s}^{-2}$, for calculation options (a) and (b) respectively. 


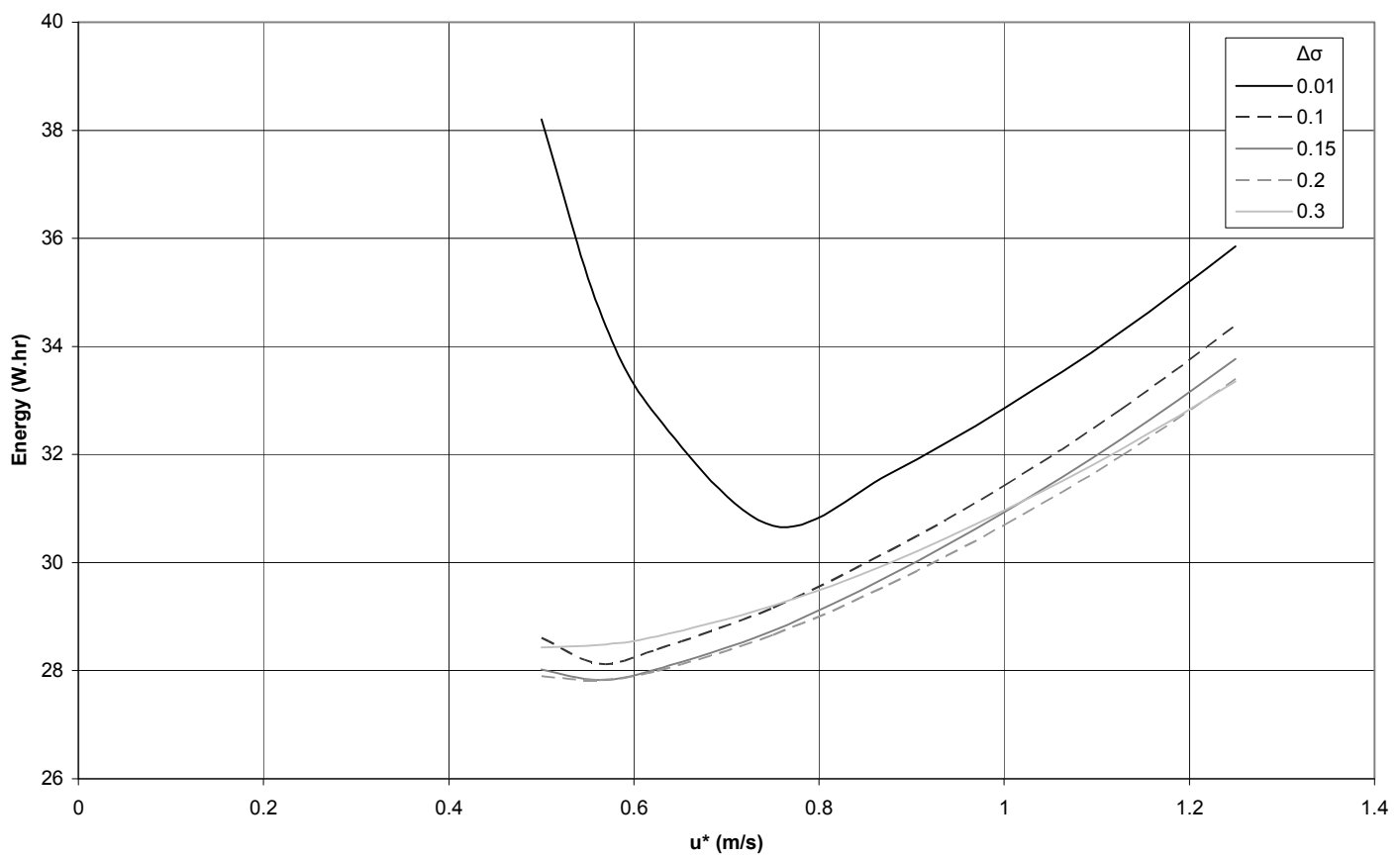

Figure 10: Energy calculation results using option (a)

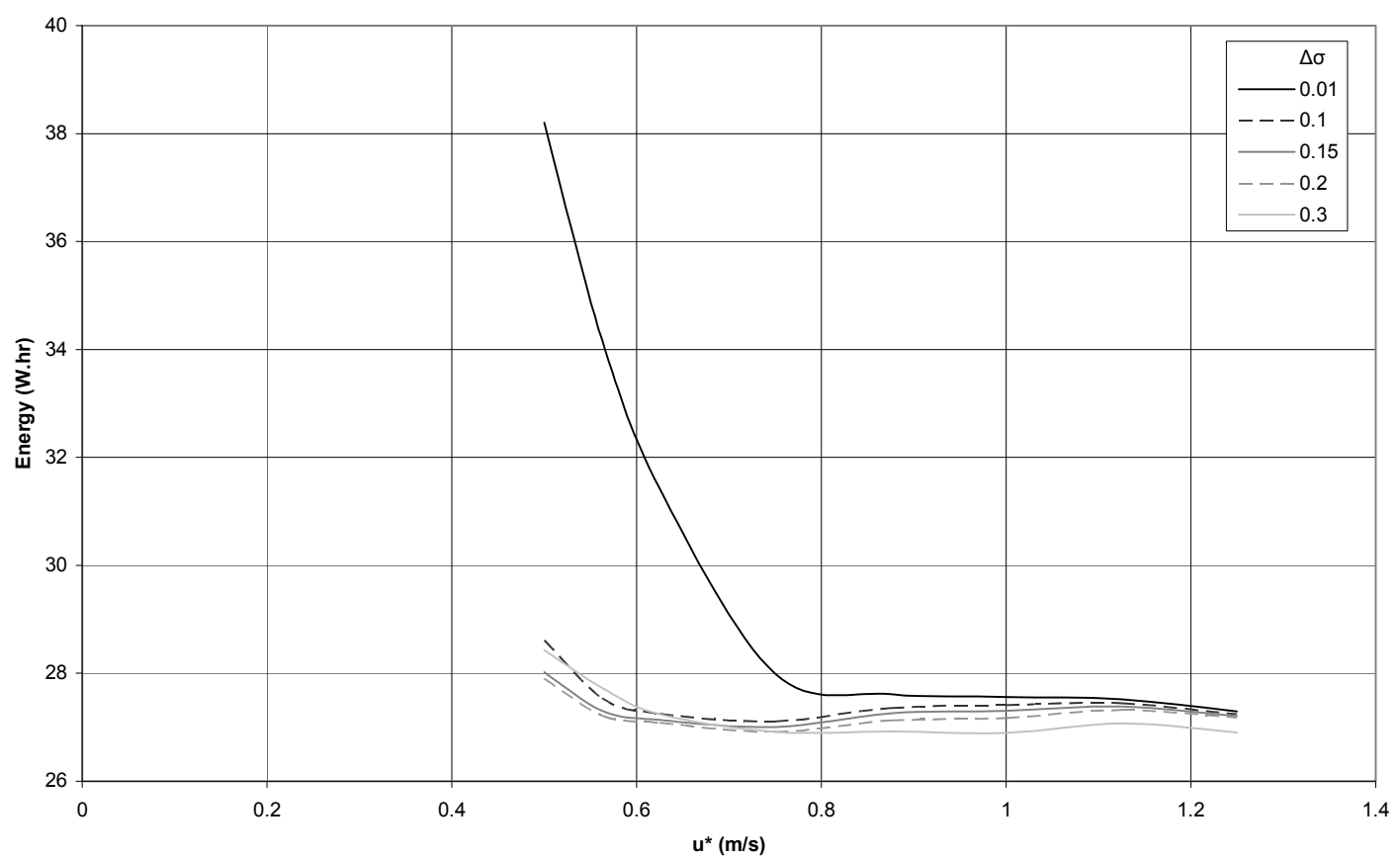

Figure 11: Energy calculation results using option (b)

Both Figures 10 and 11 show that the steepest transition $(0.01)$ is the most costly approach. Investigation of the time histories of the thruster rotational speed allows identification of the higher energy levels to be attributed to sudden jump in demand on the tunnel thruster. Both figures also show that there is little difference caused by variation of the steepness parameter. Figure 11 shows that there is little difference between the energy required across the range of mid-transition speeds when the individual transition periods are considered. If a global transition period (option (a)) is considered then there is a minimum energy point around $0.55 \mathrm{~m} \cdot \mathrm{s}^{-1}$ as shown in
Figure 10. The differences between the two figures illustrate the amount of energy that would be used in waiting for the global transition period to end. One reason that the transition energy is fairly flat in Figure 11 is that it is easier to achieve transition at higher speeds, in terms of the magnitude of the depth change to correct, but the interaction of the thruster jet with the higher speed flow means the thruster requires more energy to operate.

A series of tests was undertaken to investigate the dependency of the energy on the force required, that is, 
by how much the vehicle is positively ballasted. The results of this set of simulations (for positive buoyancy varying from $0.15 \%$ to $0.6 \%$ ) found little variation in the general form of the energy results on the force required.

In conclusion these simulations show that there is little variation in the required energy and thus the transition zone should be selected on a basis of the levels of controllability required. Furthermore, to maintain controllability the transition zone should be taken slowly with a high mid-transition speed.

The steepness of the transition zone does not have a large impact provided a step change is avoided. However, larger values of steepness increase the speed range included in the transition zone. So the steepness value selected may be influenced by a desire to have a small transition zone to simplify the overall control and enlarge the operating range of the AUV.

\section{ADDITIONAL MODEL DEVELOPMENTS}

To improve the single thruster model the influences of known suction areas downstream of the jet exit require their influences to be assessed and modelled. Thereafter multiple thrusters are considered via a thruster pair.

\subsection{SINGLE TUNNEL THRUSTER PITCH CONSIDERATIONS}

The operation of a single centrally mounted tunnel thruster on a vehicle undergoing transition will induce a nose-down pitching moment due to the low pressure region generated downstream of the thruster, see Figure 12. This simplified representation ignores the small area of relative high pressure just upstream of the thruster exit and the pressure distribution around the inlet.

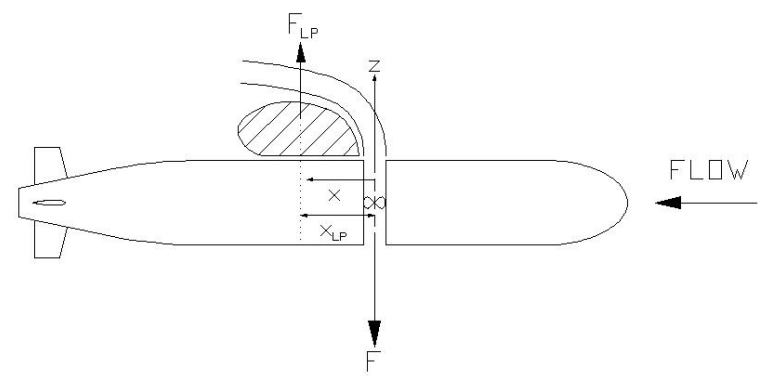

Figure 12: Moment diagram for a single tunnel thruster

It is important to be able to understand the effect that this pitching moment would have on the controllability of the vehicle, hence a model of this simplified representation is to be used. The magnitude of the pitching moment is:

$$
M=F_{\mathrm{LP}} x_{\mathrm{LP}} \text {. }
$$

Here the force generated by the low pressure region, $F_{L P}$, is assumed to be equal to the difference between the expected force generated by the thruster, Equation (10), and the actual force experienced as calculated using Equation (11).

The location of the low pressure region, and hence the moment arm of the force this low pressure region generates, is a function of how the thruster exit jet interacts with the ambient flow and hence the path the jet takes downstream. Empirical relationships [34] have been developed for the path of the jet in a crossflow as a function of velocity ratio of the form:

$$
\frac{x}{D}=\omega\left(\frac{z}{D}\right)^{\xi}\left(\frac{u}{u_{\mathrm{j}}}\right)^{\psi}
$$

This equation facilitates the calculation of the height of the jet centreline downstream of the thruster but does not provide any insight into the extent of the low pressure region. Therefore a simple approach is taken to defining the moment arm of this low pressure region using the experimentally measured forces and moments [20]. A conclusion from [35] is that the location of the centre of action of the low pressure force moves aft linearly with increasing speed ratio. A model of this form has been adopted with the coefficient, $k$, selected based on a best fit to the experimental data, that is:

$$
x_{\mathrm{LP}}=k D \frac{u}{u_{\mathrm{j}}} .
$$

With $k$ specified simulations were undertaken across the full range of mid-transition speeds and transition steepness at one deceleration, $-0.01 \mathrm{~m} \cdot \mathrm{s}^{-2}$. No alterations were made to the control strategy used. The depth profiles showed a reduced depth change with a more consistent return to the target depth across the range of mid-transition speeds.

The pitch variations showed a larger maximum pitch angle with a longer time spent with a negative pitch angle caused by the moment generated. The pitch oscillations still occur, but have a more consistent magnitude that is approximately equal to the average magnitude from the simulations without the moment included.

The energy variations show an overall decrease in energy usage attributable to the increased pitch angles and the smaller depth changes, meaning the thruster is required to do less work. The shape of the energy variations is also altered with a decrease in the energy for higher midtransition speeds (using both calculation approaches) showing that there may be a small energy benefit to transitioning at higher speeds.

The overall conclusion from these simulations is that the thruster induced pitch moment can have quite a substantial effect by inducing quite large pitch angles. However, in this case, these pitch angles benefit the operation of the vehicle and this is shown in an overall reduced energy cost. It should also be noted that the pitch moment is a function of the speed ratio, meaning it is unlikely to have an impact on the low speed manoeuvring performance of the vehicle. 


\section{2}

\section{MULTIPLE TUNNEL THRUSTERS}

An AUV which has a single centrally mounted tunnel thruster has no pitch control at zero and low forward speeds. The simulations have shown that this is not necessarily a problem, due to the righting moment of the vehicle. However, in certain situations it may be useful to have pitch control, especially when undertaking low speed manoeuvres. A possible method of adding this pitch control is to use a tunnel thruster pair, mounting one forward and one aft of the vehicle centre. A key consideration is how much energy this would require. Manipulations of Equation (14) show that the energy used by two tunnel thrusters of the same diameter as the single tunnel thruster is a factor of $(1 / \sqrt{ } 2)$ less than that required by a single tunnel thruster. The diameter of the tunnel thrusters would need to be reduced by the same factor for the energy required by both approaches to be the same. However these requirements may not be practical in terms of the available locations and space onboard the vehicle.

In order to model the AUV using two tunnel thrusters it is necessary to account for the influence of one thruster on the other. Since there is very little published data for this condition and the experiments carried out so far [20] did not cover this configuration a small set of simulations will be carried out assuming that there are no interaction effects. Future planned experiments will provide the required insight on interaction effects. The performance of the aft thruster is assumed to be the same as the forward thruster, even though in reality this is not expected to be the case given the differing shapes of the surrounding hull form and differing ambient flow conditions.

In order to include the pitching moment on the vehicle the simplified representation used for a single tunnel thruster is adopted as shown in Figure 13.

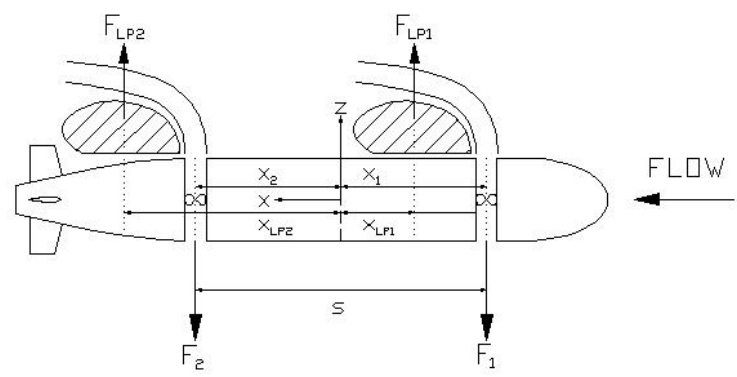

Figure 13: Moment diagram for a tunnel thruster pair

Examination of Figure 13 yields the following balance of moments:

$$
F_{1}\left|x_{1}\right|+F_{\mathrm{LP} 2} x_{\mathrm{LP} 2}=F_{2} x_{2}+F_{\mathrm{LP} 1}\left|x_{\mathrm{LP} 1}\right| \text {. }
$$

The modulus signs simply convert coordinates to levers. Again the forces due to the low pressure regions are evaluated from the difference between the force experienced by the vehicle and the expected force from the thruster. The forces and moment arms for the thrusters are the expected forces and the geometric spacing respectively. The moment arms for the low pressure regions are calculated in a similar manner to the single tunnel thruster, assuming that the thrusters are equispaced about the vehicle centre, then:

$$
\left|x_{\mathrm{LP} 1,2}\right|=\left(\frac{s}{2}\right) \mp k_{\mathrm{p}} D \frac{u}{u_{\mathrm{j}}} .
$$

The moment arm gradient, $k_{\mathrm{p}}$, is an assumed constant. This modified model has been implemented into the pitch equation of the AUV model block.

A conflict arises when trying to use the tunnel thrusters to control the pitch of the vehicle, since the tunnel thrusters would operate on a vehicle with a zero pitch angle to maximise their performance. However, to allow the controllers to drive the pitch angle to zero would prevent balancing the positive buoyancy hydrodynamically. Despite this the controller was written to order the tunnel thrusters to set a zero pitch angle. The control interchange between the control surfaces and the tunnel thrusters for the pitch was undertaken on a basis of the forward speed using Equation (12). This provides a scaled pitch demand to the tunnel thrusters. Therefore it only remains to allocate an appropriate rotational speed to each thruster to set the pitch angle. This is undertaken using an interchange function similar in form to Equation (12), allocating the proportions of the rotational speed to the two thrusters as $k_{1}$ and $k_{2}$, where:

$$
k_{1}=0.5 \tanh \left(\frac{G P_{\mathrm{d}}}{P_{\mathrm{dL}}}\right)+0.5
$$

and

$$
k_{2}=1-k_{1} .
$$

Here $P_{\mathrm{d}}$ is the pitch demand, $P_{\mathrm{dL}}$ is a pitch limit setting the extents of the pitch range for the model and $G$ is a constant that sets the steepness of the allocation. A high value of $G$ sets a steeper, more responsive allocation. (Note that the total rotational speed (or force) is dictated by the tunnel thruster depth controller as before).

A complete set of simulations at a deceleration of $-0.01 \mathrm{~m} \cdot \mathrm{s}^{-2}$ were run for this configuration. The results showed a depth change similar in magnitude to that for the single tunnel thruster (without pitch moment), but with a more consistent return to the target depth as found when including the pitch moment. The pitch curves are consistent across the range of mid-transition speeds and show a fairly large pitch angle followed by a rapid recovery to zero pitch with significantly reduced oscillations. Figure 14 shows a comparison of the pitch variations for the three configurations tested. This illustrates the large pitch angle experienced with the thruster pair and the significant reduction in the oscillations. The thruster pair curve has a non-smooth nature due to the simplicity of the thruster controller used in this complex situation. 


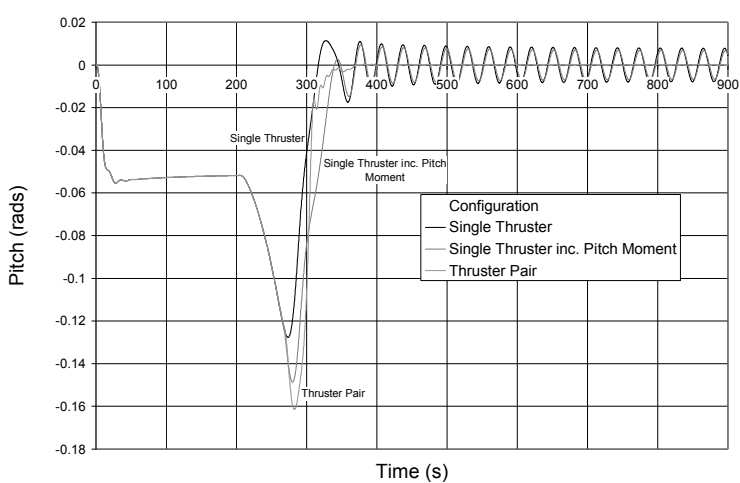

Figure 14: Comparison of pitch variations

The energy cost is similar in shape to the results for the single thruster when including the pitch moments. The energy magnitude is much reduced, but in line with that predicted by the manipulations of Equation (14), that is, reduced by a factor of approximately $(1 / \sqrt{2})$. Overall these simulations demonstrate the ability of the selected system to maintain the controllability of the AUV using a pair of tunnel thrusters to provide pitch control.

\section{PRACTICAL ISSUES}

The simulations reported in this paper demonstrate that a through-body tunnel thruster can be used to control the hydrostatic balance of an AUV undergoing the transition phase from survey operation to low speed operation. However it is also important to consider the practical impact of adopting such an approach.

The simulations have demonstrated that sufficient levels of controllability can be maintained using the tunnel thruster and hence the practical impact of using the tunnel thruster relates to the impact on the endurance of the vehicle. For the single tunnel thruster example considered, the energy required for the vehicle to hover is equivalent to the propulsion power required to propel the vehicle at $1.2 \mathrm{~m} \cdot \mathrm{s}^{-1}$ (using a simplified estimate of propulsion power [36]). Whilst undertaking the transition phase the power load required by the tunnel thruster is higher than the hovering load due to the increased forces required to overcome the depth change and the loss of performance of the tunnel thruster at higher forward speeds. This high power load leads to an increased interest in reducing the use of the tunnel thrusters. Possible approaches include reducing the positive buoyancy (and hence force required) and extending the range of performance of the control surfaces.

A practical impact of the control approach used relates to the selection of the mid-transition speed and steepness. The mid-transition speed is likely to be selected on a basis of mission objectives since it is not advisable to undertake key mission objectives whilst operating in the transition phase. The steepness is likely to be selected as a compromise between having a smoother transition, which reduces the power load and improves controllability, versus the desire to use a lower steepness to reduce the extent, in terms of speed range, of the transition zone.

\section{CONCLUSIONS}

Standard manoeuvring equations have been modified to accommodate the influences of through-body tunnel thrusters. Use of (as yet) unpublished experimental data has been made to assess the influence of the downstream flow associated with the exiting jet from the thrusters. An approach to combining stern plane control and the thruster control to reflect the changing requirements as forward speed is reduced in a flight-style transition phase to a hover condition is used to test the vehicle performance and assess the feasibility of using tunnel thrusters to control the hydrostatic balance at low speeds.

Simulations of a survey-style AUV undertaking the transition phase have been undertaken for a range of decelerations and control interchange parameters to assess their influence on the performance of the vehicle and the associated energy cost. The results demonstrate that the selection of the control parameters can be made on a basis of the levels of vehicle performance and controllability desired since the energy cost is relatively consistent for smooth transitions.

Overall these results demonstrate the ability of the tunnel thruster configurations tested to maintain vehicle control throughout the transition phase and provide a means of estimating the associated energy cost to the vehicle. The practical issues associated with using tunnel thrusters have also been considered showing the estimated power loads required. The work reported here forms part of a wider research project to investigate approaches to extending the capabilities of survey-style autonomous underwater vehicles.

\section{REFERENCES}

1. Stevenson, P., Millward, N.W., McPhail, S.D., Riggs, J., White, D., Pebody, M., Perrett, J.R. \& Webb, A.T. 'Engineering an Autonomous Underwater Vehicle for Under Ice Operations', Proceedings of the International Conference on Offshore Mechanics and Arctic Engineering OMAE, Cancun, Mexico, Vol. 3, pp. 445-452. 2003

2. Furlong, M. 'System Identification of the Hydrodynamic Characteristics of Underwater Vehicles', Engineering Doctorate Thesis, University of Southampton, UK. 2005

3. Booth, T.B., Randall, J.W. \& Hirom, C.P.J. 'Dynamic Characteristics of Submarines', Second Edition, Technical Report, AMTE Haslar, UK. 1980

4. Kimber, N.I. \& Marshfield, W.B. 'Design and Testing of Control Surfaces for the Autosub 
Demonstrator Test Vehicle', DRA Haslar Technical Report, UK. 1993

5. McPhail, S.D. \& Pebody, M. 'Autosub-1. A Distributed Approach to Navigation and Control of an Autonomous Underwater Vehicle', Proceedings of the Seventh International Conference on Electronic Engineering in Oceanography - Technology Transfer from Research to Industry, IEEE, pp. 16-22. 1997

6. Allmendinger, E.E. 'Submersible Vehicle Systems Design', SNAME, Jersey City, NJ, USA. 1990

7. Bandyopadhyay, P.R. 'Trends in Biorobotic Autonomous Undersea Vehicles', IEEE Journal of Oceanic Engineering, Vol. 30, No. 1, pp. 109139. 2005

8. Tangirala, S. \& Dzielski, J. 'A Variable Buoyancy Control System for a Large AUV', IEEE Journal of Oceanic Engineering, Vol. 32, No. 4, pp. 762-771. 2007

9. Thornton, B., Ura, T., Nose, Y.\& Turnock, S.R. 'Zero-G Class Underwater Robots: Unrestricted Attitude Control Using Control Moment Gyros', IEEE Journal of Oceanic Engineering, Vol. 32, No. 3, pp. 565-583. 2007

10. Nickell, C.L., Woolsey, C.A. \& Stilwell, D.J. 'A Low-Speed Control Module for a Streamlined AUV', Proceedings of Oceans 2005, IEEE. 2005

11. Jakuba, M.V., Yoerger, D.R. \& Whitcomb, L.L. 'Longitudinal Control Design and Performance Evaluation for the Nereus 11,000m Underwater Vehicle', Proceedings of Oceans 2007, IEEE. 2007

12. Palmer, A.R., Hearn, G.E. \& Stevenson, P. 'Modelling Tunnel Thrusters for Autonomous Underwater Vehicles', IFAC Workshop on Navigation, Guidance and Control of Underwater Vehicles 2008, Killaloe, Ireland. 2008

13. Carlton, J.S. 'Marine Propellers and Propulsion', Second Edition, ButterworthHeinemann, Oxford, UK. 2007 (See Chapter 6)

14. Beveridge, J.L. 'Design and Performance of Bow Thrusters', Marine Technology, Vol. 9, No. 4, pp. 439-453. 1972

15. English, J.W. 'The Design and Performance of Lateral Thrust Units for Ships', Transactions of RINA, Vol. 105, No. 3, pp. 251-279. 1963

16. Brix, J.E. \& Bussemaker, O. 'Lateral Thrusters with Anti-Suction Tunnels', 1st North American Tug Convention, Day 4, Paper 5, pp. 263-284, Ship \& Boat International, Vancouver, Canada, Reed Industrial Press Ltd., London, UK. 1973

17. Karlikov, V.P. \& Sholomovich, G.I. 'Some Features of Body-Flow Interaction in the Presence of Transverse Jets', Fluid Dynamics, Vol. 33, No. 3, pp. 313-317. 1998

18. Gopalan, S., Abraham, B.M. \& Katz, J. 'The Structure of a Jet in Crossflow at Low Velocity
Ratios', Physics of Fluids, Vol. 16, No. 6, pp. 2067-2087. 2004

19. Fric, T.F. \& Roshko, A. 'Vortical Structure in the Wake of a Transverse Jet', Journal of Fluid Mechanics, Vol. 279, pp. 1-48. 1994

20. Palmer, A.R., Hearn, G.E. \& Stevenson, P. 'Experimental Testing of a Autonomous Underwater Vehicle with Tunnel Thrusters', The First International Symposium on Marine Propulsors, Trondheim, Norway, 22-24 June 2009. Marintek/NTNU. 2009

21. van Lammeran, W.P.A., van Manen, J.D. \& Oosterveld, M.W.C. 'The Wageningen BScrew Series', Transactions of SNAME, Vol. 77, pp. 269-317. 1969

22. Yoerger, D.R., Cooke, J.G. \& Slotine, J.-J.E. 'The Influence of Thruster Dynamics on Underwater Vehicle Behavior and their Incorporation into Control System Design', IEEE Journal of Oceanic Engineering, Vol. 15, No. 3, pp. 167-178. 1990

23. McLean, M.B. 'Dynamic Performance of Small Diameter Tunnel Thrusters', MSME Thesis, Naval Postgraduate School, Monterey, CA, USA. 1991

24. Cody, S.E. 'Experimental Study of the Response of Small Tunnel Thrusters to Triangular and Square Wave Inputs', MSME Thesis, Naval Postgraduate School, Monterey, CA, USA. 1992

25. Healey, A.J., Rock, S.M., Cody, S., Miles, D. \& Brown, J.P. 'Toward an Improved Understanding of Thruster Dynamics for Underwater Vehicles', IEEE Journal of Oceanic Engineering, Vol. 20, No. 4, pp. 354-361. 1995

26. Bachmayer, R., Whitcomb, L.L. \& Grosenbaugh, M.A. 'An Accurate FourQuadrant Nonlinear Dynamical Model for Marine Thrusters: Theory and Experimental Validation', IEEE Journal of Oceanic Engineering, Vol. 25, No. 1, pp. 146-159. 2000

27. Blanke, M., Lindegaard, K.-P. \& Fossen, T.I. 'Dynamic Model for Thrust Generation of Marine Propellers', IFAC 5th Conference on Maneuvering and Control of Marine Craft. Aalborg, Denmark, 23-25 Aug. 2000. Elsevier, Kidlington, UK. 2000

28. Kim, J. \& Chung, W.K. 'Accurate and Practical Thruster Modeling for Underwater Vehicles', Ocean Engineering, Vol. 33, pp. 566-586. 2006

29. Saunders, A. \& Nahon, M. 'The Effect of Forward Vehicle Velocity on Through-body AUV Tunnel Thruster Performance', Proceedings of Oceans 2002, Vol. 1, pp. 250259, IEEE. 2002

30. Ananthakrishnan, P., Vantouroux, S., Zhang, K. \& Smith, S. 'Nonlinear Dynamics and Hydrodynamics Considerations in the Design of an Autonomous Underwater Vehicle', 
Proceedings of Oceanology International 1998, Brighton, UK, pp. 119-128. 1998

31. Godhavn, J.-M., Fossen, T.I. \& Berge, S.P. 'Nonlinear and Adaptive Backstepping Designs for Tracking Control of Ships', International Journal of Adaptive Control ad Signal Processing, Vol. 12, No. 8, pp. 649-670. 1998

32. Nienhuis, U. 'Simulation of Low Frequency Motions of Dynamically Positioned Offshore Structures', Transactions of RINA, Vol. 129, pp. 127-145. 1987

33. Breivik, M. \& Fossen, T.I. 'A Unified Control Concept for Autonomous Underwater Vehicles' American Control Conference, IEEE, Minneapolis, MN, USA. 2006

34. Margason, R.J. 'The Path of a Jet Directed at Large Angles to a Subsonic Free Stream', NASA-TN-D-4919. 1968

35. Chislett, M.S. \& Björheden, O. 'Influence of Ship Speed on the Effectiveness of a LateralThrust Unit', Report Hy-8, Hydro-og Aerodynamisk Laboratorium, Lyngby, Denmark. 1966

36. Furlong, M., McPhail, S. \& Stevenson, P. 'A Concept Design for an Ultra-Long-Range Survey Class AUV', Proceedings of Oceans 2007, IEEE. 2007 